УДК 811.161.125

DOI 10.23951/1609-624X-2020-2-55-60

\title{
КОНТЕКСТНЫЕ МАКРОСТРУКТУРЫ КАК МЕХАНИЗМ ФОРМИРОВАНИЯ ДИАЛОГИЧЕСКИХ МОДЕЛЕЙ КОММУНИКАЦИИ В ДИСКУРСЕ СОЦИАЛЬНО-СЕТЕВОГО РАДИО
}

\section{Л. И. Ермоленкина}

\section{Томский государственный педагогический университет, Томск}

\begin{abstract}
Введение. Современные конвергентные формы медийной коммуникации демонстрируют разнообразные способы и модели взаимодействия агентов дискурса (журналистов, авторов и ведущих программ) и клиентов - адресатов, получивших в сетевом пространстве статус пользователей, участников интеракций, создателей информационного и развлекательного контента. Дискурсивная практика радио в социальных сетях формируется под влиянием технологических процессов интеграции, на основе ценностных систем, принципов взаимодействия с адресатом, сформированных в традиционном, аналоговом вещании и в сетевых аккаунтах интернета.

Материал и методы. Дискурсивный анализ, направленный на выявление специфики диалогической коммуникации, позволяет определить роль контекстных макроструктур в построении и развитии сценариев коммуникативного взаимодействия. Контекстные макроструктуры социально-сетевого радио, функционирующие на пересечении дискурсивных практик радио и веб-коммуникации, определяют прагматические установки субъектов интеракций, тематическую прогрессию и семантические репрезентации дискурса. В качестве материала рассматриваются тексты развлекательного радио Махітum социально-сетевого аккаунта «ВКонтакте».

Результаты и обсуждение. Анализ речевой структуры социально-сетевой версии канала выявил следующие закономерности в реализации диалогических моделей коммуникации, формируемых под воздействием контекстных макроструктур. На основе аудиального кода радийной макроструктуры формируется согласованная диалогическая модель: участники интеракций используют кооперативную стратегию взаимодействия при обсуждении музыкальных текстов. Макроструктура социально-сетевой коммуникации реализует преимущественно конфликтную модель, актуализируя эгоцентрическую стратегию взаимодействия. Установка коммуникантов на аналоговую форму трансляции (линейную коммуникацию от источника к слушателям) реализуется в межсубъектной модели взаимодействия, что находит свое выражение в общности картин мира коммуникантов. Доминирование в речи социально-сетевой макроструктуры определяет квазимежсубъектный сценарий развития диалога, подчиняющийся принципам аффилиации - присоединения к сказанному с целью актуализации в публичном пространстве.

Заключение. Данная модель не демонстрирует эксплицитных маркеров диалогичности, но может быть рассмотрена с точки зрения успешной коммуникации, если учитывать дискурсивную перспективу социально-сетевого радио и основополагающую ценность ее картины мира - установку на развлечение.
\end{abstract}

Ключевые слова: развлекательное радио, дискурс радио в соииальных сетях, диалогические модели коммуникачии, контекстные макроструктуры.

\section{Введение}

Последнее десятилетие в истории СМИ характеризуют процессы технологической интеграции традиционных форм вещания и интернета, определяющие новые аспекты функционирования и развития медийных источников, их дискурсивных практик и картин мира [1-3]. В данной работе рассматриваются те изменения, которые произошли в дискурсивной практике радио под влиянием социально-сетевых коммуникаций. В результате технологических преобразований структура радиовещания в интернете стала качественно иной - зависимой от коммуникативной активности и творческой энергии адресата, получившего в пространстве сетевых аккаунтов радио статус основного субъекта дискурса, автора и создателя его контента, формируемого в диалогической коммуникации разговорных чатов.

\section{Материал и методы}

Взаимодействие субъектов социально-сетевого дискурса радио удовлетворяет определенным кри- териям интерактивности, представленным, в частности, в работах Д. Матисона. Автор описывает интерактивность медиа в категориях выбора пользователем того, как он может потреблять информационно-коммуникационный ресурс, создавая свое собственное содержание [4, с. 234].

Интерактивное взаимодействие коммуникантов в социально-сетевом дискурсе радио характеризуется адресной поливекторностью: сообщение может быть (1) направлено определенному участнику коммуникации, когда власть над течением разговора реализуется в двустороннем порядке, и (2) адресовано неопределенному количеству пользователей. В этом случае взаимодействие становится асимметричным, отдаленным от того взаимонаправленного и обоюдно настроенного разговора, который происходит между людьми в обыденных контекстах. Кроме того, участник интерактивного взаимодействия становится актором целого комплекса действий - он делает нечто более сложное, чем слушает и отвечает: вступает в социальное 
взаимодействие, реагируя на коммуникативные и когнитивные стимулы собеседников, с одной стороны, и институционального дискурса - с другой. В этом случае коммуниканты действуют как участники аксиологической системы знаков, формируемой идеологическими структурами радиодискурса: его форматной концепцией, тональностью, моделями построения диалога.

Интенции взаимонаправленного внимания оформляются в различные виды диалогического общения с фатической, прагматической, информационной, дискуссионной целеустановками на пересечении ценностных картин мира. Сущность диалогической коммуникации, по М. М. Бахтину, раскрывается в активном понимании, раскрытии другого и целостно неделимом взаимодействии с ним. В этом случае диалогическая встреча направлена на познание и самопознание. В качестве критериев состоявшегося диалога исследователь указывает такие характеристики, как «уникальность и принципиальное равенство коммуникантов, взаимная дополнительность их позиций, ожидание ответа в процессе общения и его предвосхищение в собственном высказывании» [5, с. 143].

Существенное значение для диалогической коммуникации имеют условия той дискурсивной практики, в границах которой она протекает. Так, интерактивное взаимодействие, организуемое в медийных дискурсах, указывает на моделируемый характер диалога, его обусловленность технологическими особенностями источника (программное обеспечение интернет-ресурсов) и его идеологии системы ценностных установок, психологических ожиданий, устоявшихся форм и способов общения, «предзнания», по У. Эко [6, с. 137], диктующих нормы употребления языка и видения мира.

Диалогический характер коммуникации радио в социально-сетевом пространстве обусловлен: 1) особенностями интеркодового характера дискурca, формируемого на пересечении практик радио и веб-коммуникации; 2) коммуникативными и социально-психологическими ожиданиями адресата.

Следует подчеркнуть, что мотивационные основания субъектов социально-сетевого дискурса радио обусловлены социально-психологическими презумпциями сетевой культуры, согласно которым интернет-общение воспринимается как имитация реального взаимодействия, восполняющее социальные и межличностные дефициты коммуникации, с одной стороны, и с другой - как способ высвобождения игровой энергии, потребности коммуниканта проживать роли и ситуации, не заданные жизненными обстоятельствами, формировать в этом процессе свою идентичность, искать созвучные собственным идеи, ценности, представления о должном [7, с. 26]. Таким образом, интенции адре- сата, характер его включенности в дискурс определяют содержательное наполнение и динамику информационно-коммуникационной практики радио социально-сетевого формата. Анализ материала радиотекстов социально-сетевой версии развлекательного канала «Махіmum» - позволяет говорить о том, что взаимодействие коммуникантов отражает дискурсивные модели коммуникации, которые эксплицированы дискурсивными макроструктурами. Термин «макроструктура», в концепции Т. ван Дейка, эксплицитно представляет общие топики текста и одновременно характеризует общую связность (когерентность текста) [8, с. 129]. На примере анализа новостного дискурса автор выявляет зависимость связности текста от тематической макроструктуры (набора топиков) всего новостного дискурса. К этому же выводу приходят и другие исследователи: «Тематическая целостность обеспечивается иерархией его макроструктур, производных от дискурса» [9, с. 86].

\section{Результаты исследования}

Анализируемый материал позволяет уточнить понятие макроструктура применительно к анализу спонтанной коммуникации, протекающей в границах социально-сетевого дискурса радио. Под макроструктурой в данном случае понимается способ структурирования модели взаимодействия коммуникантов, связанный с представлением о контексте - дискурсивной практике радио или социальносетевой коммуникации. Специфика реализации данной макроструктуры проявляется в зависимости моделей коммуникации (согласованность/конфликтность) от общей модальности дискурса, его аксиологического содержания, коммуникативных сценариев, выработанных в процессе дискурсивной практики радио или социально-сетевых интеракций. Таким образом, макроструктуру можно рассматривать как общую схему его формально-содержательной организации, которая задается дискурсом и реализуется в определенных сценариях диалогического взаимодействия.

В этом аспекте дискурсивного анализа, учитывающего фактор контекстуальности, текст рассматривается как продукт институционального дискурса, проекция его параметров на определенный фрагмент действительности. При этом адресат (индивидуальный или массовый) подчиняется правилам дискурсивной среды, в которой они создают или воспринимают текст, используя соответствующие механизмы порождения или интерпретации текста.

Влияние дискурсивных макроструктур обнаруживает себя в актуализации тех границ, которые сдерживают или определенным образом направляют взаимодействие субъектов коммуникации, 
определяя характер прагматических установок, тематической прогрессии и семантических репрезентаций дискурса.

Анализ материала выявил следующее: 1) макроструктура радио эксплицируется в речи коммуникантов в установках на личностный план взаимодействия, предполагающей согласованность с музыкальным кодом радио, его форматной концепцией, системой идентификационных ролей, выбираемых участниками для общения: любитель отечественного/зарубежного рока, «хорошей музыки» и т. д.; 2) макроструктура интернет-коммуникации реализуется в дискурсе сетевого радио как социально маркированный хронотоп, построенный на механизме аффилиации - психологической потребности в одобрении, поддержке, социальных связях, устанавливаемых в том числе с целью актуализации в публичном пространстве [7, с. 28].

Экспликация в дискурсивной практике радио социально-сетевой или радийной макроструктуры формирует разные модели диалогического взаимодействия: 1) межсубъектную («субъект - хозяин речи» П. Серио [10]) и 2) квазимежсубъектную (дискурс приписывает определенное положение любому субъекту [11]).

Адресная активность в рамках первой модели направлена к определенному участнику, и контроль над течением разговора реализуется в двустороннем порядке. Взаимодействие в рамках второй модели характеризуется асимметричностью, отсутствием установки на взаимонаправленный разговор. По сути, можно говорить о квазинтеракции, когда точки коммуникативного сопряжения выстраиваются не последовательно, а ризомно, т. е. «принципиально неструктурно, неиерархично, нестабильно, нонфинально....» [12, с. 829], образуя текстовую целостность в перспективе дискурсивной практики - в случайных и намеренных пересечениях субъектов коммуникации, имитирующих диалогические структуры.

Взаимодействие участников сетевых интеракций радио «Махіmum» происходит под влиянием семиотического кода, определяющего ценностные основы механизма идентификации. В высказываниях коммуникантов аксиологический модус субкультурного маркирования эксплицирован в тактиках указания музыкальных групп как ценностных ориентиров: «Aаaа, можно побольше Green Day, My Chemical Romance, Arctic Monkeys u Black Veil Brides» ${ }^{1}$. В качестве маркера субкультурной стратификации участниками коммуникации используется тактика отстройки: Убрали нормальную музыку, даже Цоя! А как его раньше по ночам крутили,

\footnotetext{
1 Здесь и далее цитаты из текстов радио в социальных сетях приводятся с опорой на источник: https:/vk.com/topic70634941_33780914?post=6259
}

невероятно радостно от этого было! И напихали такой ерунды в эфир! Хоть плачь!

Реализация аксиологического кода дискурса прослеживается в выборе тех коммуникативных тактик, которые максимально координируют личностные и речевые планы коммуникантов. Об установке на диалогическое взаимодействие в рамках межсубъектной модели свидетельствует временной отрезок - реплики собеседников выстраиваются в целостную, хронологически, модально и тематически оформленную интеракцию, соответствующую принципам диалогического взаимодействия:

Марина Аллабергенова 3 окт. в 13:49

Да, 2003... Rasmus, Linkin park, H.I.M., Rammstein... именно с этих групп я и увлеклась рок музыкой))

Александр Александров 3 окт. в 13:44

Помню у меня их плакаты из журнала «Молоток» на стене висели. Помню клипь смотрел на дисковом плеере iRiver с маленьким встроенным монитором... Эх ностальгия.

Анна Селибакина 3 окт. в 13.39

А я запомнила больше клип с воронами. Хотя, вообще все 3 версии были хороши.

Истинность подобного диалога с точки зрения его бытийно-философского характера может быть достаточно относительной. Еще Ж. Бодрийяр говорил о спекулятивности интенций, опосредованных медийным контекстом: смоделированные опыт и чувства способствуют тому, что мы теряем способность воспринимать реальность саму по себе [13].

В аспекте дискурс-анализа факт связной структуры коммуникации указывает на успешный характер ее протекания. При оценке общения с точки зрения его результативности значимы такие показатели, как наличие кооперативной стратегии, общей позиции [14] или принципа речепсихической координации [15].

Взаимонаправленная речевая активность собеседников реализуется на основе общей позиции, понимаемой как «сумма общих, совместных знаний, мнений и допущений, на основе которых субъекты коммуникации могут координировать свое общение, что выражается в совпадении языковых, речепсихических репрезентаций, свидетельствует о нересурсозатратности и неконтролируемости общения» [15, с. 439$]$.

Двусторонний характер взаимодействия обеспечивает тематическую прогрессию речи коммуникантов, сохранение в процессе взаимообмена ее тематического ядра. Диалогическая модель, сформированная на основе радийной макроструктуры, разворачивается в межличностную коммуникацию, для которой значим личный опыт восприятия музыки и событий, ассоциируемых с нею. Исповедальный тон, характерный для диалогической модели, указы- 
вает на сформированность ценностной установки, в границах которой коммуниканты транслируют личностно значимые смыслы. Это позволяет говорить о том, что в основании коммуникации лежит не только потребность в самоактуализировании и самовыражении, требующая присутствия другого, но и потребность в построении личностно значимой картины мира, ее ценностной концептуализации. При этом фатически ориентированная цель проявляется в установке на достижение доверительных отношений, эмоциональной открытости. Таким образом, под воздействием макроструктуры радио взаимодействие достигает личностного плана диалога, речевой фатический регистр способствует сближению картин мира говорящих, обеспечивая диалогическую результативность дискурса.

Иной аспект взаимодействия в пространстве веб-коммуникации радио реализуется под воздействием социально-сетевой макроструктуры, проявляющейся в установках на выражение в публичном пространстве своей позиции, убеждений без поиска ответной реакции. Реплики коммуникантов в рамках данной модели не демонстрируют диалогической взаимонаправленности, что характерно подтверждает их хронологическая фиксация: длительность интервалов между репликами может достигать нескольких месяцев. Дискурсивным механизмом вовлечения в сетевое общение в разговорных чатах радио становится принцип «присоединения к сказанному» на основе эгоцентрической стратегии самоактуализации и утверждения собственного «Я». Здесь мы наблюдаем характерное для односторонней коммуникации отсутствие кооперативной стратегии, принципов координации и эксплицитных маркеров обратной связи.

Особенность реализации сетевой интернет-коммуникации радио, на наш взгляд, проявляется в том, что дискурсивный сценарий развития подобного взаимодействия также коммуникативно успешен и диалогически результативен с точки зрения дискурсивной практики социально-сетевой формы радио.

Процесс взаимодействия структурирован в текстовом контенте по принципу нанизывания - каждая новая реплика, являясь реакцией на тему, актуализированную в инициальном высказывании или в последующих репликах коммуникантов, как бы наслаивается на предыдущие, частично пересекаясь с ними в аспекте темы. Когнитивными скрепами подобной коммуникации являются оценочные импликатуры, фиксирующие границы определенной модальной установки: одобрять, критиковать, иронизировать, дискредитировать и т. д. На основе данных установок в дискурсе формируются диалогические структуры - цепи высказываний, не отражающие в своем целеполагании установку на диалог, но создающие эффект диалогичности в дискурсивной перспективе: для вновь присоединившегося к коммуникации.

Виталий Иванов 12 мая 2016 в 20:24

O, «инкубатор российских исполнителей» Владимира Киселева заработал! Поздравляю всех, вот мы и окончательно про@рали станичию!

Денис Лисиц 22 мая 2015 в 22:09

Пожелание в принципе для вещзания, что за жесть вы крутить начали? Я понимаю разбавить контент русским роком, но деревенские быдло песни про индейцев с нулевым смыслом и убогим исполнением это перебор, не преврашиайтесь в НАШЕ РАДИО пожалуйста!

Ольга Лобанова 13 фев. 2015 в 17:52

Ну вот как слушать радио, если Светлана Зейналова все портит? ("Семью восемь - сорок восемь!» Я не придираюсь, просто она ВСЕ свои глупости с такой уверенностью заявляет, что аж бесит. И сразу переключаюсь на другую волну (()

Леонид Такеев 12 янв. 2015 в 15:36

Даешь рок вместо всякой nоnсоть!! Sum 41, blink 182, yellowcard, fall out boy, disturbed, red, breaking benjamin, 36 crazyfists... я долго могу продолжать).

Светлана Блюм 15 янв. 2015 в 20:24

Хотелось бы немного разбавить весь этот негатив и недовольства в данном обсуждении. Хочу выразить свое восхищение ребятам из утреннего шоу! Саша, Оля и Игорек, вы умнички, с вами никогда не бывает скучно! А после новогодних праздников включив утренний эфир очень поразило, удивило и очень порадовало наличие новых игр, развлечений аудитории! И конечно неожиданно было усльишать русскую музыку, но ее не так много, и кроме Шнура илака нет. Еще раз спасибо вам ребята за хорошее настроение по утрам!!!

Александр Наривончик 11 окт. 2014 в 13:24

Насчет плей-листа. Сейчас он соответствует формату станичи начала 2000-х, когда собственно и начал слушать максимум. Но после ухода с радио старых ведущих пару лет были не лучшими в истории станциии, в плей-листе появились исполнители, которых было привычно сльишать скорее на русском радио, чем на максимум. Достойных русских исполнителей очень мало, поэтому может и хорошо, что убрали совсем. Я бы добавил очень ограниченное их количество.

Данный фрагмент не обнаруживает основных параметров успешной коммуникации: взаимной позиции коммуникантов, установки на кооперацию, маркеров обратной связи. Казалось бы, подобное взаимодействие не может быть квалифицировано как диалогическое. Согласно концепции фазовой коммуникации Кларка [16], каждый коммуникативный акт состоит из двух фаз: презентации и принятия. Этот момент достижения точки 
взаимной координации очевидно отсутствует в представленных репликах, но в то же время динамика развертывания диалогических структур, проявляемая в ансамбле ролей (провокатор, аналитик, одобряющий), эмоционально-оценочной амплитудности (дискредитация, критика, похвала) определяет эффект успешного взаимодействия в дискурсивной перспективе - с точки зрения любого субъекта, вступившего в пространство сетевого общения и рассматривающего его как пространство игровое, ценностно поливариантное. В этом случае механизм развития диалогических структур заключается не в логической последовательности вопросно-ответной формы, а в аксиологическом и ассоциативном характере его построения.

\section{Заключение}

Диалогическое взаимодействие субъектов в аккаунте социальных сетей радио реализовано в границах двух моделей, специфически «реагирующих» на контекстные макроструктуры радио и сетевой коммуникации. При этом доминирование радийной макроструктуры определяет личностный характер взаимодействия и способствует формированию диалогического общения. Социально-сетевая макроструктура актуализируется в выборе коммуникантами стратегий виртуальной сетевой практики, указывающей на важность такой ценностной категории дискурсивной картины мира, как развлечение, установка на самоактуализацию в пространстве публичных дискурсов.

\section{Список литературы}

1. Ермоленкина Л. И. Дискурсивная личность в коммуникативном пространстве современного радио // Вестник Томского гос. пед. ун-та (TSPU Bulletin). 2017. Вып. 2 (179). С. 37-40.

2. Костяшина Е. А. Механизмы дискурсивных трансформаций коммуникативной модели «автор - адресат» в текстовом пространстве научно-популярного медицинского журнала // Язык и культура. 2010. № 2 (10). С. $22-28$.

3. Резанова 3. И., Скрипко Ю. К. Личность в среде дискурса: языковая репрезентация социально-психологических типов // Вестник Томского гос. ун-та. Филология. 2016. № 3 (41). С. 37-56.

4. Матисон Д. Медиадискурс. Анализ медиатекстов. Исследования медиа и культуры. Харьков: Гуманитарный центр, 2017.

5. Бахтин М. М. Эстетика словесного творчества. М.: Искусство, 1986.

6. Эко У. Отсутствующая структура. Введение в семиологию. М.: Simposium, 2004.

7. Кузнецов В. Г. Влияние СМИ на традиционное понимание социализации // Язык и дискурс средств массовой информации в XXI веке. М.: Академический проект, 2011. С. 19-30.

8. Дейк Т. ван. Анализ новостей как дискурса // Язык. Познание. Коммуникация. М.: Прогресс, 1989. С. 111-160.

9. Негрышев А. А. Новости в прессе: к моделированию макротекстовой структуры // Язык и дискурс средств массовой информации в XI веке. М.: Академический проект, 2011. С. 85-97.

10. Серио П. Анализ дискурса во французской школе (Дискурс и интердискурс). М.: Академический Проект; Екатеринбург: Деловая книга, 2001.

11. Фуко М. Археология знания. СПб.: ИЦ «Гуманитарная Академия»; Университетская книга, 2004.

12. Новейший философский словарь. Минск: Книжный дом, 2003.

13. Бодрийяр Ж. Система вещей. М., 1995, 2001 // Центр гуманитарных технологий. URL: https://gtmarket.ru/laboratory/basis/3496 (дата обращения: 10.03.2008)

14. Pickering M. J., Garrod S. Automaticity in language production in monologue and dialogue // Meyer A.S., Wheeldon L.R., KrottA. (eds) Automaticity and control in language processing. Hove: Psychology Press, 2007.

15. Федорова О. В. Экспериментальный анализ дискурса. М.: Языки славянской культуры, 2014.

16. Clark H. On Stochastic grammar // Language. 2005. 81 (1).

Ермоленкина Лариса Ивановна, доцент кафедры теории языка и методики обучения русскому языку, Томский государственный педагогический университет (ул. Киевская, 60, Томск, Россия, 634000).

E-mail: arblar2004@rambler.ru

Материал поступил в редакичию 09.01.2020.

\section{DOI 10.23951/1609-624X-2020-2-55-60}

\section{CONTEXT MACRO-STRUCTURES AS THE MECHANISM OF FORMING DIALOGICAL MODELS OF COMMUNICATION IN SOCIAL WEB-RADIO DISCOURSE}

\section{I. Yermolenkina}

Tomsk State Pedagogical University, Tomsk, Russian Federation

Introduction. The article discusses the principles of organizing a dialogue between users of social networks of entertainment radio. Modern convergent forms of media communication are realized at the intersection of discursive macrostructures. In particular, radio functions in social networks of the Internet as a multifactorial phenomenon, depending on the technological and ideological features of media sources, such as radio and the Internet. 
The innovative nature of the traditional source of information is manifested in the position of the addressee, which is due to the capabilities of the Internet user. The one-way communication method of analog radio acquires the qualities and capabilities of an interactive interaction model, the listener becomes a user, an active subject of discourse, his agent and content generator.

Results and discussion. The analyzed material allows us to draw the following conclusions. The method of dialogue depends on the dominant macrostructures, which are either analog radio or social networkcommunication.

The indicated macrostructures realize themselves at the level of values and the ideology of network communication. The macrostructure of the radio is explicated in the speech of the communicants in settings on the personal plan of interaction. The macrostructure implements an intersubject model of interaction.

The macrostructure of social network communication manifests itself in the psycho-speech mechanisms of affiliation, namely, in the connection of speakers to the speech in order to actualize in public space, realizing a quasi-subject communication model.

The second model does not show explicit markers of dialogue, but can be considered from the point of view of successful communication, given the general discursive perspective and the social-network form of organization of communication.

Keywords: entertainment radio, discourse of radio in social networks, dialogical models of communication, context macro-structures.

\section{References}

1. Yermolenkina L. I. Diskursivnaya lichnost' v kommunikativnom prostranstve sovremennogo radio [Discursive person in communicative space of modern radio]. Vestnik Tomskogo gosudarstvennogo pedagogicheskogo universiteta - TSPU Bulletin, 2017, no. 2, pp. $37-40$ (in Russian).

2. Kostyashina Ye. A. Mekhanizmy diskursivnykh transformatsiy kommunikativnoy modeli "avtor - adresat" v tekstovom prostranstve nauchnopopulyarnogo meditsinskogo zhurnala [The mechanisms of discourse transformations in the communicative model "author - addressee" in text space of health magazines]. Yazyk i kul'tura - Language and Culture, 2010, no. 2 (10), pp. $22-28$ (in Russian).

3. Rezanova Z. I., Skripko Yu. K. Lichnost' v srede diskursa: yazykovaya reprezentatsiya sotsial'no-psikhologicheskikh tipov (na materiale diskursa virtual'nykh fan-soobshchestv muzykal'noy napravlennosti [Personality in the medium of discourse: linguistic representation of psychological types (based on the discourse of virtual music fan communities)]. Vestnik Tomskogo gosudarstvennogo universiteta. Filologiya - Tomsk State University Journal of Philology, 2016, no. 3 (41), pp. 37-56 (in Russian).

4. Matison D. Mediadiskurs. Analiz mediatekstov. Issledovaniya media i kul'tury [Discourse of media. Analysis of media texts. Media and Culture Studies]. Kharkov, Gumanitarnyy tsentr Publ, 2017 (in Russian).

5. Bakhtin M. M. Estetika slovesnogo tvorchestva [Esthetics of verbal art]. Moscow, Art Publ, 1986 (in Russian).

6. Eco U. Otsutsvuyushchaya struktura. Vvedeniye v semiologiyu [Missing structure. Introduction in semiology]. Moscow, Simposium Publ, 2004 (in Russian).

7. Kuznetsov V. G. Vliyaniye SMI na traditsionnoye ponimaniye sotsializatsii [The influence of the media on the traditional understanding of socialization]. Yazyk i diskurs sredstv massovoy informatsii $v$ XXI veke [Language and discourse of mass media in XXI century]. Moscow, Akademicheskiy proyekt Publ., 2011. Pp. 19-30 (in Russian).

8. Van Dijk T. Analiz novostey kak diskursa [Analysis of news as a discourse]. Yazyk. Poznaniye. Kommunikatsiya [Language. Cognition. Communication]. Moscow, Progress Publ., 1989. Pp. 111-160 (in Russian).

9. Negryshev A. A. Novosti v presse: k modelirovaniyu makrotekstovoy structury [News in press]. Yazyk i diskurs sredstv massovoy informatsii v XXI veke [Language and discourse of mass media in XXI century]. Moscow, Akademicheskiy proyekt Publ., 2011. Pp. 85-97 (in Russian).

10. Serio P. Analiz diskursa vo frantsuzskoy shkole (Diskurs i interdiskurs) [Discourse analysis in a French school (Discourse and interdiscourse)]. Moscow, Akademicheskiy Proyekt Publ., Yekaterinburg, Delovaya kniga Publ., 2001 (in Russian).

11. Fuko M. Arkheologiya znaniya [The archeology of knowledge]. Saint Petersburg, Gumanitarnaya akademiya Publ., Universitetskaya kniga Publ., 2004 (in Russian).

12. Noveyshiy filosofskiy slovar' [New philosophical dictionary]. Moscow, Knizhniy dom Publ., 2003 (in Russian).

13. Bodriyyar Zh. Sistema veshchey [The system of items]. Moscow, Tsentr gumanitarnykh tekhnologiy Publ., 1995, 2001 (in Russian). URL: https:/l gtmarket.ru/laboratory/basis/3496 (accessed 10 March 2008).

14. Pickering M. J., Garrod S. Automaticity in language production in monologue and dialogue. In: Meyer A. S. Wheeldon L. R. Krott A. (eds) Automaticity and control in language processing. Hove, Psychology Press, 2007.

15. Fyodorova O. V. Eksperimental'nyy analiz discursa [Experimental discourse analysis]. Moscow, Yazyki slavyanskoy kul'tury Publ., 2014. 512 p. (in Russian).

16. Clark H. On Stochastic grammar. Language, 2005, 81 (1).

Yermolenkina L. I., Tomsk State Pedagogical University (ul. Kiyevskaya, 60, Tomsk, Russian Federation, 634000). E-mail: arblar2004@rambler.ru 